\title{
Including adolescent migrants in school through VET approach: evidence from a pilot action in Italy
}

\author{
Valentina Lamonica* ${ }^{*}$, Elena Ragazzi and Lisa Sella
}

\author{
${ }^{*}$ Correspondence: \\ valentina.lamonica@ircres. \\ cnr.it \\ CNR-IRCrES, Via Real Collegio \\ 30, 10024 Moncalieri, TO, Italy
}

\begin{abstract}
This paper investigates the effectiveness of a small experimental pilot addressed to foreign adolescents with low language skills and high dropout risk in lower secondary school in Turin, North-West Italy. The intervention aims at reducing Early School Leaving while supporting standard school curricula. In order to facilitate students' re-motivation and their attachment to the school environment, the pilot proposes an original VET approach that alternates standard school activities to innovative vocational training. In particular, treated students substitute 290 h VET courses for 10 standard school weeks along a scholastic year. First of all, the analysis aims at evaluating effects on Early School Leaving. Then, since the pilot requires a long period in VET away from school, the study evaluates effects on educational outcomes. Oltre I Muri is a very small pilot experiment, involving seven schools and offering 11 VET positions to migrant students. We investigated the effectiveness of the program by an experimental counterfactual approach: participants have been randomly assigned to a treated and a control group with similar characteristics. They are adolescent migrants attending the 2 nd year of lower secondary school and manifesting very high drop-out risk. Treated students attend the alternating VET/school pilot, while control students attend standard school classes. Randomization inference allows assessing average treatment effects, but the very small sample size does not guarantee statistical significance at standard levels. Results anyhow suggests some effectiveness of the project in contrasting Early School Leaving. In particular, while some non-treated students dropped out from school during the pilot, all treated students regularly completed their scholastic year. This can be interpreted as a $20 \%$ increase in school attendance, with an $80 \%$ confidence level assessed by Montecarlo randomization. Finally, extreme value bound techniques applied to test scores suggest that treated students do not prejudice their learning by attending VET instead of standard school classes during the pilot. On the contrary, their school attachment is reinforced.
\end{abstract}

Keyword: Vocational education, Disadvantaged young, Early school leaving, Counterfactual analysis in this article are included in the article's Creative Commons licence, unless indicated otherwise in a credit line to the material. If material is not included in the article's Creative Commons licence and your intended use is not permitted by statutory regulation or exceeds the permitted use, you will need to obtain permission directly from the copyright holder. To view a copy of this licence, visit http://creativeco mmons.org/licenses/by/4.0/. 


\section{Introduction and motivation}

In the present situation of growing migration dynamics of children and adolescents, Italian compulsory school is still far from being truly effective in migrants' integration. To avoid marginalisation, on their arrival in Italy young foreigners are generally enrolled with peers. This choice encourages their social inclusion thanks to age proximity, but it is effective only if recent arrivals represent a small fraction of the class composition. In fact, when the class displays an important number of foreign students with low Italian language skills, teachers cannot target them with the necessary personalised teaching. Hence, these students need complimentary support, e.g. from public programs or private actions from no profit organisations.

This paper investigates a pilot (named "Oltre I Muri", OIM from now on) aimed at preventing Early School Leaving (ESL) among non-EU migrant adolescents at high dropout risk in lower secondary education. Concerning the young migrants, the project aims at restoring students' interest in education by professionally oriented teaching, individual mentorship, and innovative inductive pedagogic methods. In fact, previous projects based on work-oriented and individually targeted actions proved to be effective in the social integration of weak brackets of the population (Benati et al. 2013; Ragazzi 2014; Sella 2014; Falavigna et al. 2015; Ragazzi and Sella 2016; Lamonica et al. 2016a, b).

In Italy, school attendance is compulsory until the age of 16, even though high Early School Leaving rates are experienced. As a matter of fact, in 2018 the 0.7\% of lowersecondary students dropped out, while during the transition from the lower to the upper secondary school the dropout rate was $0.5 \%$ (MIUR 2019). The analysis of data by citizenship shows that Early School Leaving affects foreigners more than Italians. In fact, in 2018 the percentage of foreign pupils who dropped out of school was $2.9 \%$ compared to the $0.5 \%$ of Italian pupils. Moreover, first-generation foreigners are in a situation of greater difficulty than second-generation ones, with a dropout rate of $4.1 \%$ with respect to $1.8 \%$.

In order to face the ESL issue, Oltre I Muri project was aimed at migrants attending the lower secondary school, with problems in school integration, from both a pedagogical point of view and a social perspective.

The paper is organized as follows. "Migrants' achievement and inclusion in education" frames up the literature, analysing in depth strategies of social and educational inclusion of young migrants; "The "Oltre I Muri" pilot as a tool to contrast migrants' ESL" describes the pilot, the target population, and the specific pedagogical approach adopted; "Methods and data" motivates the methodological approach and describes the experimental design; "Results and discussion" discusses the main results, and "Conclusions" concludes.

\section{Migrants' achievement and inclusion in education}

In order to prevent and tackle ESL in society, it is fundamental to detect the main factors causing it. Literature proposes a wide set of aspects, ranging from school-based explanations (school segregation), to individual, family, and socio-economic characteristics (Thibert 2013). Being a migrant is one of the most relevant predictors of school dropout, especially if associated with a low socio-economical background (Hippe and Jakubowski 
2018). In Europe, the percentage of students leaving school during compulsory education is twice larger among foreigners (born abroad) than among natives (EACEA 2014). The disadvantage of migrant students clearly emerges also when analysing NEET (Not in Education, Employment or Training) data, which refer to people aged 15-29. In Italy, this condition concerns $34.0 \%$ foreign students, but "only" 23.2\% native students (Lodigiani and Santagati 2017). Several studies on ethnic educational inequalities show that students with a migration background suffer from a double disadvantage: they perform worse compared to native students both because they generally have fewer socio-economic resources and because of their migratory status itself (European Commission 2013; Black et al. 2013; Ohinata and Van Ours 2012).

Beyond that, insufficient language skills, age at migration, lack of parental support (in terms of both cultural and economic capital), and the characteristics of the host educational system are other relevant determinants of young migrants' educational disadvantage (Contini 2013). In particular, national educational curricula are designed for native students, hence those with migrant background may have more difficulties to understand and learn contents that are far away from their knowledge heritage.

In this context, the ability to master the host country language is fundamental to overcome disadvantage in the school environment, which represents an essential step for social inclusion. However, this ability depends a lot from the language that students speak at home and from their age at migration (Osadan and Reid 2016). These elements are very important to understand the relevance of language skills in achieving educational integration. Attending preschool in the host country is fundamental for both socialisation and vocabulary improvement. Likewise, attending the entire secondary school path in the host country means receiving literacy and numeracy skills, thus overcoming the gap that characterises students who migrate in late adolescence (Bratsberg et al. 2012; Ohinata and Van Ours 2012). Several papers claim that a late arrival in the host country can negatively affect language proficiency, thus preventing social inclusion because of the vocabulary deficit (Dronkers et al. 2014; Dustmann et al. 2012; Beck et al. 2012).

In order to reduce youth disadvantage and prevent ESL, European countries implement different measures and programs that carry out prevention, intervention, and compensation actions (EACEA 2014). Prevention policies aim to support students at risk (i.e., education guidance, positive discrimination measures). Intervention policies are addressed to students who have experienced school failures or difficulties, and engage them through language support, scholastic support, absenteeism management, networking with parents and other actors. Finally, compensation measures aim at reintegrating dropout students in the educational system (i.e., second chance education system). The Oltre i Muri project falls into the category of intervention measures, because it involves a target population at high dropout risk and it provides language support, remotivation, and new chances to complete the compulsory educational path. In fact, one main innovation of the project is its ability to adopt a work-oriented approach, through Vocational Education and Training, in a measure implemented in the context of lower secondary education.

Concerning the proper pedagogical approach to enhance migrants' school success, literature highlights the importance of three elements. Firstly, small class size can reduce 
students' disadvantage, specifically in the case of migrants, minorities, and pupils with poor socio-economical background (Schanzenbach 2014; Andersson 2007; Nusche 2009; Björklund et al. 2005).

Secondly, including teachers with migrant background in the classroom can positively influence educational outcomes but also students' engagement. Sharing with a teacher or tutor a similar migration path can develop students' self-confidence and increase their motivation. Moreover, the tutor becomes a mediator for students with poor linguistic background (Carrington and Skelton 2003). This approach actually overcomes the methodological debate between the idea that migrants' educational achievement passes through their mother language and the opposite theory promoting no use of mother language in the educational context to easily include foreign students in the host country (Christensen and Stanat 2007).

According to Geboers et al. (2013), there is a third theoretical perspective that deserves to be taken into account. It refers to studies concerning the effects of citizenship education on pedagogical climate at school. From literature, it emerges that citizenship education by means of school curriculum appeared to be directly effective on pedagogical climate and indirectly on school inclusion, e.g. fairness and positive perception of the school environment, sense of belonging to the class group (Khoury-Kassabri and BenArieh 2008; Fjeldstad and Mikkelsen 2003). Beyond that, students' performance seems to be also related to school participation. In fact, it is demonstrated that students that are more participative in school life, both in terms of individual and collective participation, are also more willing to perform better at school (Losito and D'Apice 2003).

\section{The "Oltre I Muri" pilot as a tool to contrast migrants' ESL}

The pilot presented in the following pages is part of a larger project, funded by the national AMIF (Asylum Migration and Integration Fund), aimed at preventing Early School Leaving among foreign adolescents in Italy.

The main objective of the project is to foster the educational inclusion of non EU-students with manifested behavioural disorders (for instance the tendency to be excluded by classmates, difficult relationships with peers or teachers, lacking participation to school activities, non-satisfactory improvements in knowledge and skills). The project is addressed to students coming from public lower secondary schools and Provincial Centres for Adult Education. ${ }^{1}$ Besides other actions involving families, educators, teachers and experts from other countries (Battuello et al. 2018), one activity of the project consists in the development of a pilot involving migrant adolescents attending the 2nd lower secondary grade, that teachers report at high drop-out risk.

The pilot offers an original educational path alternating Vocational Educational Training (VET) and ordinary school, to experiment innovative learning methodologies that can stimulate students' motivation. Through this alternation, students are stimulated

\footnotetext{
${ }^{1}$ Provincial Centres for Adult Education (CPIA) provide welcome and orientation services to all citizens who are at least 16 years old. CPIA frequently enrol foreign minors aged 16 or more for the attainment of the lower secondary diploma. It is important to notice that, in Italy, foreign minors in compulsory education are enrolled in the class corresponding to their age, upon checking their skills and preparation level. If a migrant minor enrols in an educational path when the school year has already started and his educational attainment level is lower than peers, he is temporary enrolled in CPIA courses.
} 
to break their stalemate and they have the possibility to learn in a new and dynamic context.

Within the full project, the AMIF fund arranged a small amount of money to test the pilot in a specific suburban area in Turin, North-West Italy, where schools experience huge presence of migrant students and many families suffer low economic conditions. On the whole, funds allowed to offer 11 VET positions. The pilot involved a local VET centre $^{2}$ and seven lower secondary schools, each one reporting about three migrant students at high dropout risk, enrolled in the second year. ${ }^{3}$ School teachers played an essential role in the target selection, by identifying and reporting migrant students with the highest risk of Early School Leaving. This process was led by researchers, who built a common tool (questionnaires) to detect students' fragility. After this first "reporting phase", all selected students were interviewed by the VET centre staff (psychologist, counsellors, and vocational teachers) in order to check students' eligibility for the action.

The effectiveness of the pilot was investigated by counterfactual impact evaluation methodologies (see next section), implying random assignment of eligible students in a treated and a control group. Among the 22 selected students, 11 have been included in the treated group and 10 in the control group by complete random assignment, while the remaining one moved home (and school) before the assignment. If the small size of the treated group is imposed by funding limits, the poor size of the control group is due to the ethical problem of involving disadvantaged students without offering them concrete support activities. In fact, the intervention model is only addressed to the treated group, while the control group was simply involved in the collection of outcome variables necessary to the evaluation.

Concerning the intervention model, the 11 treated students moved to the VET centre twice a week during their school days, in order to follow educational paths and professional laboratories. As explained in "Migrants' achievement and inclusion in education", the small size of the class is essential to reduce students' disadvantage (Schanzenbach 2014). Concretely, students have been involved in a 290-h path, occurring at the training centre, attending both classes devoted to basic school subjects (Italian, Mathematics, and English) for a total of 90 and $200 \mathrm{~h}$ of professional laboratories (cooking, graphic design, bartender). It corresponds to 10 school weeks out of 34, i.e. about one third of standard school time. According with the methodology of learning-by-doing, students had the possibility to assimilate basic skills, knowledge and abilities acquired in the classroom within the laboratories. This educative model is based on a work-related and inductive notion of knowledge and learning, which means that students are stimulated to deepen theoretical subjects by means of laboratory practice. For instance, cooking practice can be used for learning mathematics: fractions and proportions are easily understood in practical contexts. Beyond that, the pedagogical approach has been individually targeted: during the classes at the VET centre, each student could rely on a professional tutor, with the double function of educational support and linguistic mediation.

\footnotetext{
$\overline{2}$ The project was conceived and promoted by Piazza dei Mestieri, a private Italian foundation that implements various actions addressed to young people in disadvantage.

${ }^{3}$ In principle, the alternation path targets all lower secondary school students. However, in agreement with schools, the experimental pilot involved just the second grade, since third year students are going to sit their diploma exam, while first year students are just arrived and are quite young to move independently to reach the VET centre.
} 
In order to promote educational inclusion, peer tutors (i.e. former migrant students now working at the training centre) got involved in the educational process: they had the possibility to share their personal experiences and encourage the inclusion process through peer learning. As a matter of fact, several studies demonstrate that these professionals and peer tutors are able to improve students' motivation, producing positive effects on educational inclusion (Zecca and Mazzei 2018; Fiorucci and Catarci 2015).

Finally, during the pilot, some citizenship education activities have been implemented, aimed at fostering migrants' social inclusion (Geboers et al. 2013). As an example, the pedagogical intervention constantly combines cultural elements that belong to both the host and the foreign heritage (e.g., recipes during cooking classes, discussions on habits in Italy compared to homeland, etc.).

\section{Methods and data}

The analysis of the pilot is intended to describe the impact of the vocational and educational training program described in par. 3, which aims at contrasting school drop-out of non-EU migrant lower secondary school students at high risk of Early School Leaving.

In particular, the evaluation addresses three fundamental questions, raised by school teachers and other educational staff:

- Is the pilot effective in contrasting early school leaving among lower secondary school migrant students?

- Does the pilot strengthen students' basic knowledge skills?

- Does the pilot hinder students' learning, since they miss $290 \mathrm{~h}$ of standard school classes?

In this context, the experimental randomization approach represents a fair causal test, ${ }^{4}$ aimed at estimating the average impact of the treatment on participants. In social field experiments, causal inference is particularly challenging, because of difficult experimental setting-up, intrinsic variability, randomization issues, and substitution bias (Heckman and Smith 1995). However, the nature of the OIM pilot as a tool to contrast migrants' ESL project is particularly suitable to field experimentation, which allows researchers to estimate the impact of pilot interventions carried on small samples in real-world settings (Shadish et al. 2002; Duflo 2006; Gerber and Green 2012).

In fact, the pilot provided just a small number $(m)$ of VET positions $(m=11)$, while migrant lower secondary school students eligible for the treatment were twice as many. In particular, the $N$ eligible students were assigned by complete randomization ${ }^{5}$ to either the treated or the control group, respectively obtaining $m$ treated units and $N-m$ not treated units.

\footnotetext{
${ }^{4}$ Random assignment implies that both observable and unobservable background attributes affecting outcomes are equally likely to be present in both treatment and control groups.

${ }^{5}$ Complete random assignment allocates exactly the $m$ desired number of units to the treatment: each unit has the same probability to be allocated, and the treatment status is statistically independent of units' potential outcome and background attributes. Practically, random numbers were assigned to eligible students, then they were sorted and the first $m$ selected into treatment.
} 
Within the potential outcome framework, the difference-in-means estimator, that measures the difference between the average outcome $Y$ of treated and control units, can be used as an unbiased ${ }^{6}$ estimator of the Average Treatment Effect (ATE), i.e.

$$
\widehat{A T E}=\left[\frac{\sum_{i=1}^{m} Y_{i}}{m}\right]-\left[\frac{\sum_{i=m+1}^{N} Y_{i}}{N-m}\right] .
$$

Specifically, two types of outcome indicators are analyzed: the count of school dropouts and the test scores in basic subjects. In particular, the pilot addresses Italian skills as a key factor for socio-scholastic integration (Bratsberg et al. 2012; Ohinata and Van Ours 2012), both through dedicated Italian classes and as the means of communication during practical laboratory activities. Scores were collected at the beginning of the project, to assess students' initial level, and at the end of the project, to appreciate their final outcome.

Since the project is a tool to contrast migrants' ESL, the pilot is characterized by a very small sample and different types of outcome variables (counts, scores), hypothesis testing is assessed by randomization inference, which does not rely on large-sample theory, but rather calculates p-values based on the inventory of a large number of possible randomizations (Heß 2017; Good 2005).

The experiment controls other biases that are common in experimental settings. Concerning attrition and substitution bias, an eligible student moved house (and school) just before the program started and was not replaced. In this case, we can hypothesise that attrition is random and independent from potential outcome, hence it does not affect ATE estimates. ${ }^{7}$

On the contrary, non-random attrition occurred when a couple of counterfactual students dropped out from school in the middle of the pilot. This fact represents a result per se, since the pilot was mainly aimed at contrasting school dropout, and no case occurred in the treatment group. However, dropouts' final test scores are missing, seriously undermining ATE inference based on those outcomes (Dinardo et al. 2006; Huber 2012). A cautious and simple approach to deal with non-random attrition in small samples consists of using extreme value bound techniques (Manski 1999) to calculate extreme bound ATEs, i.e. the largest and the smallest possible ATEs calculated by filling missing values by the highest and lowest outcomes respectively. This approach imposes few assumptions, but it generally generates very large extreme bounds, which are weakly informative (Gerber and Green 2012).

\section{Random assignment in practice}

Discarding the ex-ante attrition complete randomization assigned 11 treated units and 10 control units. Such very small sample size certainly allows a descriptive perspective,

\footnotetext{
${ }^{6}$ Unbiasedness is guaranteed by randomization whenever excludability and non-interference assumptions are fulfilled The excludability assumption is satisfied as long as non-treated students do not receive any extra-treatment at school. The non-interference assumption is satisfied as long as non-treated subjects are not affected by the treatment of other subjects, which is the case of this VET pilot

7 This is the so called MIPO assumption, Missing Independent of Potential Outcomes (Gerber and Green 2012). It implies that missing observations can be simply discarded in estimates.
} 
Table 1 Eligible students' treatment status and descriptive statistics

\begin{tabular}{lllll}
\hline & \multicolumn{4}{l}{ Assigned treatment status } \\
\cline { 2 - 5 } & Treated & Not treated & $\begin{array}{l}\text { Ex ante } \\
\text { attrition }\end{array}$ & Total \\
\hline Total \# by status & 11 & 10 & 1 & 22 \\
Female \# (\%) & $3(0.27)$ & $2(0.20)$ & - & $5(0.24)$ \\
Male \# (\%) & $8(0.73)$ & $8(0.80)$ & - & $16(0.76)$ \\
Age (avg) & 14.20 & 14.18 & - & 14.19 \\
Italian born \# (\%) & $3(0.27)$ & $2(0.20)$ & - & $5(0.24)$ \\
Years in Italy (avg) for non-Italian born & 2.71 & 4.25 & - & 3.53 \\
Not Italian speaking family \# (\%) & $5(0.45)$ & $4(0.40)$ & - & $9(0.43)$ \\
\hline
\end{tabular}

Absolute and percentage values

while questioning statistical significance at standard levels. However, randomization guarantees unbiased inference of the average treatment effects (ATEs).

Table 1 shows some descriptive statistics comparing treated and control units, which appear quite homogeneous in observables. In both samples, age is about 14, females count $20-27 \%$, as well as 2 nd generation migrants (Italian-born), and about half families (40-45\%) do not speak Italian at home. As described in "Migrants' achievement and inclusion in education", the language spoken at home is fundamental in order to rapidly improve students' skills and encourage their social inclusion (Osadan and Reid 2016). For this reason, it is not surprising that many families of the youngster involved in the pilot do not communicate in the language of the host country. Finally, some differences are observed, when considering years of residence in Italy, which are on average 1.5 times larger among controls.

\section{Results and discussion}

This section sheds some light on the effects of the Oltre I Muri pilot on Early School Leaving, analyzing both school attendance rates and the test scores on basic subjects (Italian, Mathematics, English).

School attendance is intended as the completion of the current scholastic year, i.e. the student did not dropout from his scholastic path (2nd year of the lower secondary school). It represents a crude but fundamental indicator, since the target population exhibits high dropout risk.

At the end of the experiment, all treated students still attend school, while two out of ten non-treated students actually dropped-out. In practice, if the treatment effect TE is defined as the difference in school attendance between the treated and the control groups, the OIM effectis $T E=\frac{11}{11}-\frac{8}{10}=0.2$, i.e. the treatment causes a $20 \%$ increase in students' school attendance. It is important to establish whether this result has some statistical significance, or it is due to chance. Because of the very small sample, this point cannot be investigated by relying on large-sample theory, but rather on randomization inference. In practice, a Montecarlo test based on 100,000 permutations ${ }^{8}$ established

\footnotetext{
${ }^{8}$ The test involves $28,3 \%$ of all possible permutations, given the actual experiment size.
} 


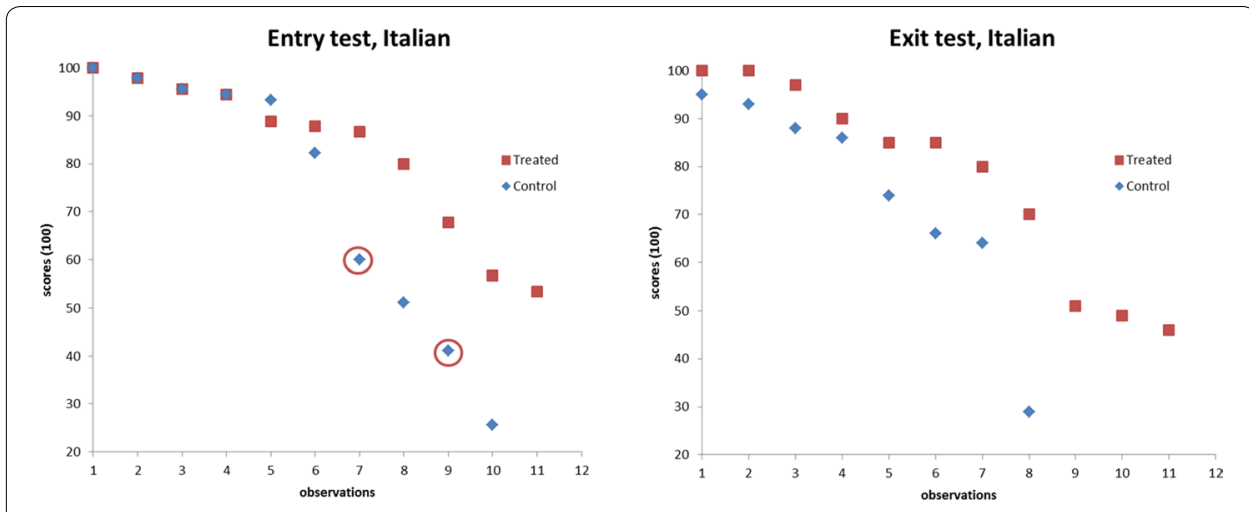

Fig. 1 Italian test scores: pre-treatment (left panel) and post-treatment (right panel) comparing treated vs. non treated

that, under the sharp null hypothesis of no treatment effect, ${ }^{9}$ there is a $21.7 \%$ chance of obtaining the very same TE value by a random assignment of observed outcomes, i.e. $\mathrm{p}$-value $=0.2168$. Hence, the statistical significance is limited and far from standard values, but results are quite satisfactory given the actual size of the experiment.

Concerning test scores, they give additional information on the educational support supplied by the pilot. As explained in "The "Oltre I Muri" pilot as a tool to contrast migrants' ESL", the OIM pilot aims at producing positive effects on students' knowledge skills by means of inductive teaching methodologies. In synthesis, the program provides a total of 290 VET hours in alternation with standard school classes within a school year, including $30 \mathrm{~h}$ per basic subject (Italian, Mathematics, English). At the beginning of the experiment, school teachers were afraid of negative effects due to this alternation format: during VET days, treated students miss school classes. In this context, evidence from test scores in basic subjects is particularly important to detect significant skill mismatch.

Basic subjects' tests were developed by VET teachers and administered twice, at the beginning and at the end of the pilot. Both the Italian and the English language tests were designed to assess students' comprehension in a communicative context, based on the Common European Framework of Reference for Languages (Verhelst et al. 2009). Tests were conceived in order to evaluate skills on a $0-100$ points range. All of them produced similar results, ${ }^{10}$ hence we limit our discussion to Italian tests.

Figure 1 plots both pre- and post-treatment Italian test scores (left and right panel, respectively). Table 2 shows that pre-treatment gap between treated and control units (i.e. the different path between squares and diamonds in the plot) is purely random and statistically not significant. ${ }^{11}$ Circled diamonds highlight dropouts' pre-treatment scores, i.e. the initial scores of those students who left school before the end of the pilot. Both occurred in the counterfactual sample.

\footnotetext{
${ }^{9}$ The sharp null hypothesis of no treatment effect is $Y_{i}\left(D_{i}=0\right)=Y_{i}\left(D_{i}=1\right)$, i.e. potential outcome is the same independently of treatment status $D$.

10 Pearson's correlation coefficients calculated between pairs of basic subjects pre-tests are in the range [0.88;0.93].

11 The Welch's t-test statistic for independent treated and control samples does not allow to reject the null hypothesis that treated and the control units have on average the same pre-treatment score ( $\mathrm{p}$ value $=0.391$ ).
} 
Table 2 Italian test scores: pre- and post-treatment descriptive statistics

\begin{tabular}{lllllll}
\hline & \multicolumn{2}{l}{ Pre-treatment } & & \multicolumn{2}{l}{ Post-treatment } \\
\cline { 2 - 3 } & Treated & Not treated & & Treated & Non treated \\
\hline Total observations & 11 & 10 & & 11 & 8 \\
Average score (points) & 82.6 & 74.1 & & 77.5 & 74.3 \\
Std. dev & 16.4 & 27.3 & & 19.6 & 20.4 \\
Max & 100 & 100 & & 100 & 95 \\
Min & 53 & 26 & & 46 & 29 \\
T-test for mean equality (p value) & 0.391 & & & & 0.750 & \\
\hline
\end{tabular}

In our framework, the ATE can be estimated by the difference in average test score (outcome variable) between the treated and the control samples. However, in this case ATE estimation is biased because of non-random attrition. Table 2 shows that the posttreatment difference in mean scores between treated and not treated units is +1.2 . However, the two dropouts occurred in the counterfactual sample produce two missing outcomes. This causes the bias, since dropout behavior cannot be considered independent either from the outcome variable or from the assignment to treatment. In fact, we have already noticed that dropout occurred just in the counterfactual, probably as a consequence of the pilot effectiveness.

A strategy to face this bias in ATE estimation is offered by extreme value bound techniques (Manski 1999), which fill missing outcomes with the highest and lowest possible outcome values, in order to estimate the upper and lower ATE bounds respectively. Nevertheless, in this case we can take advantage of pre-treatment test information, which is highly predictive of the final scores. ${ }^{12}$ The circles in Fig. 1 show that dropouts' initial scores are in the middle of the counterfactual distribution. Hence, we can hypothesize that missing scores are bound within the observed range of final scores in the counterfactual sample.

Therefore, to calculate proper ATE bounds, the two missing outcomes are filled at first with the maximum value observed in the counterfactual sample $(95 / 100)$, then with the minimum (29/100). Finally, the upper (lower) ATE bound is assessed by computing the difference between the average outcome among the treated, which is fully observed, and the average outcome among controls when missing values are filled with the maximum (minimum) value observed in the counterfactual sample. Calculations show that ATE is bound between +12.2 and -0.9 points, i.e. on average treated students show scores between 12 points higher and 1 point lower than controls. On a 0-100 scale, this result corresponds to an ATE between +12 and $-1 \%$ in Italian comprehension skills.

Hence, ATE estimates based on test scores cannot confirm a strictly positive impact of the pilot on students' knowledge; however, the difference-in-mean ATE estimate shows that, in the worst case, non-treated students perform on average $1 / 100$ points better than the treated ones, which is a very negligible outperformance. In the best case, treated students outperform controls of more than one grade over ten.

\footnotetext{
12 Basic subject scores are supposed to be highly persistent over the course of a year (the pilot duration). In fact, in the counterfactual group, Italian entry scores predicted the $83 \%$ of the variance in the final scores, as measured by the coefficient of determination $\mathrm{R}^{2}$ obtained by regressing $Y_{i}(0)$ on the corresponding pre-test values.
} 
Notwithstanding these results are assessed on a very small sample, they suggest that participation of migrant students to similar projects does not compromise their knowledge with respect to standard school paths. Probably the pilot devotes a too small amount of hours to basic subjects to produce unambiguous results. Rather, it seems appreciable the effect of the pilot in contrasting Early School Leaving.

\section{Conclusions}

This paper investigates the effectiveness of a small experimental pilot aimed at reducing Early School Leaving while supporting standard school curriculum. It is addressed to foreign adolescents with low language skills and high dropout risk in lower secondary school.

In order to facilitate migrant students' re-motivation and their attachment to the school environment, the pilot proposes an original VET approach, that alternates standard school activities and innovative vocational training. Such approach is unusual in lower secondary education in Italy, but this alternation stimulates students to break their stalemate and to learn in a new and dynamic context. The pilot has been jointly conceived by school and VET educational staff, and its pedagogical approach displays some key elements proved by literature to enhance migrants' school success: small class size (Schanzenbach 2014; Andersson 2007; Nusche 2009; Björklund et al. 2005); tutors with migrant background (Zecca and Mazzei 2018; Fiorucci and Catarci 2015); focus on citizenship education (Geboers et al. 2013). The students involved in the pilot attend VET instead of school twice a week, for a total of about one third scholastic year. Funding devoted to test the pilot allowed to offer 11 VET positions in a specific suburban area in Turin, North-West Italy, characterized by high migrants' concentration and low socioeconomic conditions.

Our analysis aims at evaluating the effects of the pilot on Early School Leaving and educational outcomes. Using a counterfactual approach, 21 students were involved and completely randomized to a treated and a control group. Notwithstanding standard statistical significance levels cannot be reached due to small sample, results are quite encouraging. In particular, 2 out of 10 non treated students dropped out from school during the pilot, while all treated students continued to attend regularly. This can be interpreted as a treatment effect of $20 \%$ increase in school attendance, which can be attributed to the pilot at an $80 \%$ confidence level by randomization inference (He $\beta$ 2017; Good 2005). When discussing results for validation, school teachers observed that treated students showed differentiated improvement in learning, but all of them clearly manifested a strong impact on scholastic motivation. Results are quite supportive also when considering the impact on students' linguistic skills. In this case, it was necessary to adopt extreme value bound techniques to assess the average treatment effect (Gerber and Green 2012; Manski 1999). This strategy overcomes non-random attrition (the two non-treated dropouts), but it produces large extreme bounds, that are weakly informative. Anyhow, calculations on Italian test scores show that on average treated students' scores are between 12 points higher and 1 point lower than controls. On a 0-100 scale, this corresponds to an ATE between +12 and - $1 \%$ on Italian comprehension skills. Clearly, these calculations cannot confirm a strictly positive impact of the pilot on students' knowledge. However, in the worst 
case, non-treated students perform $1 / 100$ points better than the treated ones, while in the best case, treated students outperform controls of more than one grade over ten.

In conclusion, all these positive results strongly encourage the enlargement of the pilot to wider experiments, taking into account some lessons learned during this study, in order to improve both the intervention model and the method of investigation. In particular, the need for larger samples (and larger funds) is fundamental to strengthen the statistical significance of the estimates, as well as some complementary qualitative approaches that are fundamental in order to better interpret emerging results. Further research should also focus on tailored tests aiming at profiling students at the beginning of the programme. In fact, the characteristics of the target population are often unexplored, while language barriers may prevent school teachers from detecting migrants' actual abilities. Nevertheless, tailored tests are fundamental to enhance the effectiveness of the action, since establishing the initial level is essential to design well-suited learning paths. Finally, it is important to further investigate the role of the host language as a key factor for social inclusion: pure linguistic skills (i.e., reading and listening comprehension, writing, speaking) and character skills jointly define individual ability to communicate. One major strength of the OIM pilot is its innovative pedagogical approach, jointly working on linguistic and social abilities, while more traditional educational approaches mainly focus on technical linguistic teaching.

If corroborated by stronger scientific evidence, the approach proposed in this pilot could be a precious tool to help schools and their teachers integrating migrant students in standard curricula. This is particularly compelling in societies that are characterized by increasing foreign immigration. This is the case of Italy, where the compulsory educational system is mainly designed for native students, but there is an increasing concentration of young migrants, who are waiting for better common strategies aiming at their socio-scholastic integration.

\section{Abbreviations}

ATE: Average Treatment Effect; CPIA: Provincial Centres for Adults Education; DID: Difference-in-differences estimators; ESL: Early school leaving; TE: Treatment effect.

\section{Acknowledgements}

The authors would like to show their gratitude to the project managers of Piazza dei Mestieri: Mauro Battuello and Monica Pillitu for their constant collaboration and support.

\section{Authors contributions}

All authors contributed substantially to this work. In particular, ER raised funding for the evaluation project and agreed the evaluation design with the project leader. LS and VL designed the field study and collected the data. Data analysis for this paper was conducted by LS in consultation with all other authors. All authors were involved in the interpretation and discussion of the results. All authors read and approved the final manuscript.

\section{Funding}

This study was funded by the Italian Ministry of the Interior, under the national AMIF grant (Asylum Migration and Integration Fund).

\section{Availability of data and materials}

The data used and analysed during the current study are available from the corresponding author on reasonable request.

Competing interests

The authors declare that they have no competing interests.

Received: 7 October 2019 Accepted: 26 July 2020

Published online: 31 July 2020 


\section{References}

Almlund M, Duckworth AL, Heckman J, Kautz T (2011) Personality psychology and economics. In: Hanushek EA, Machin S, Woessmann L (eds) Handbook of the economics of education, vol 4. Elsevier, Amsterdam, pp 1-181

Andersson C (2007) Teacher density and student achievement in Swedish compulsory schools. In: Working Paper, vol 4. Institute for Labour Market Policy Evaluation (IFAU), Uppsala.

Barbaranelli C, Caprara GV, Rabasca A, Pastorelli C (2003) A questionnaire for measuring the Big Five in late childhood. Personal Individ Differ 34(4):645-664

Battuello M, Dinocca R, Strano C, Ragazzi E, Lamonica V, Sella L, Pillitu M, Traversa G (2018) Beyond Walls. Models of integration. Building a transnational community of educators to welcome young foreigners into the school system, Fondazione Piazza dei Mestieri, Turin.

Beck A, Corak M, Tienda M (2012) Age at immigration and the adult attainments of child migrants to the United States. Ann Am Acad Polit Soc Sci 643(1):134-159

Benati I, Ragazzi E, Sella L (2013) Valutare l'impatto della Formazione Professionale sull'inserimento lavorativo: lezioni da una ricerca in Regione Piemonte. RIV Rassegna Italiana di Valutazione XVI(56-57):26-47. https://doi.org/10.3280/ RIV2013-056003

Bergin C, Bergin D (2009) Attachment in the Classroom. Edu Psychol Rev 21:141-170

Björklund AM, Clark MA, Edin PA, Fredriksson P, Kreuger AB (2005) The market comes to education in Sweden: an evaluation of Sweden's surprising school reforms. Russell Sage Foundation, New York

Black SE, Devereux PJ, Salvanes KG (2013) Under pressure? The effect of peers on outcomes of young adults. J Labor Econ 31(1):119-153

Bowlby J (1988) A secure base: parent-child attachment and healthy human development. Routledge, London

Bonini E, Santagati M (eds) (2016) Primo Rapporto. Osservatorio sulla dispersione scolastica delle scuole secondarie di secondo grado del Comune di Milano. Milano, Fondazione ISMU, Comune di Milano

Bratsberg B, Raaum O, Røed K (2012) Educating children of immigrants: closing the gap in Norwegian schools. Nord Econ Policy Rev 3(1):211-251

Carrington B, Skelton C (2003) Re-thinking 'Role Models': equal opportunities in teacher recruitment in England and Wales. J Educ Policy 18(3):253-265

Christensen G, Stanat P (2007) Language policies and practices for helping immigrants and second-generation students succeed. The Transatlantic taskforce on immigration and integration. Migration Policy Institute (MPI) and Bertelsmann Stiftung, Washington, D.C

Commodari E (2013) Preschool teacher attachment, school readiness and risk of learning difficulties. Early Child Res Q 28:123-133

Cook PJ, Dodge K, Farkas G, Fryer RG Jr, Guryan J, Ludwig J, Mayer S, Pollack H, Steinberg L (2014) The (surprising) efficacy of academic and behavioral intervention with disadvantaged youth: results from a randomized experiment in Chicago (No. w19862). National Bureau of Economic Research, Cambridge

Contini D (2013) Immigrant background peer effects in Italian schools. Soc Sci Res 42(4):1122-1142

Costa PT Jr, McCrae RR (1990) Personality disorders and the five-factor model of personality. J Pers Disord 4(4):362-371

Devaux-Spatarakis A (2014) L'expérimentation «tellequ'elle se fait »: leçons de troisexpérimentations parassignation aléatoire. Formation emploi 126:17-38. http://formationemploi.revues.org/4180

Di Nardo J, McCrary J, Sanbonmatsu L (2006) Constructive proposals for dealing with attrition: an empirical example. NBER Working Paper.

Dinno A (2009) Exploring the sensitivity of Horn's parallel analysis to the distributional form of random data. Multivar Behav Res 44(3):362-388

Dronkers J, Levels M, de Heus M (2014) Migrant pupils'scientific performance: the influence of educational system features of origin and destination countries. Large-scale Assess Educ 2(1):3

Duflo E (2006) Field experiments in development economics. Econ Soc Monogr 42:322

Dunn OJ (1964) Multiple comparisons using rank sums. Technometrics 6:241-252

Durlak JA, Weissberg RP, Dymnicki AB, Taylor RD, Schellinger KB (2011) The impact of enhancing students' social and emotional learning: a meta-analysis of school-based universal interventions. Child Dev 82(1):405-432

Dustmann C, Frattini T, Lanzara G (2012) Educational achievement of second-generation immigrants: an internationa comparison. Economic Policy 27(69):143-185

European Commission/EACEA/Eurydice/Cedefop (2014) Tackling early leaving from education and training in Europe: strategies, policies and mesures. Eurydice and Cedefop Report. Publication Office of the European Union, Luxembourg

European Commission (2013) Study on Educational Support to newly arrived migrant children. Publication Office of the European Union, Luxembourg

Falavigna G, Ragazzi E, Sella L (2015) Gender inequalities and labour integration. An integrated approach to vocational training in Piedmont. Politica Econ J Econ Policy XXXI(1):97-120. https://doi.org/10.1429/80538

Fiorucci M, Catarci M (2015) Intercultural education in the European context: theories, experiences, challenges. Routledge, London

Fjeldstad D, Mikkelsen R (2003) Strong democratic competence does not automatically lead to strong engagement and participation. Int J Educ Res 39:621-632

Geddes H (2006) Attachment in the Classroom: the links between children's early experience, emotional wellbeing and performance in school. Worth Publishing, London

Geboers E, Geijsel F, Admiraal W, ten Dam G (2013) Review of the effects of citizenship education. Educ Res Rev 9:158-173

Gerber AS, Green DP (2012) Field experiments: design, analysis, and interpretation. WW Norton, New York

Goldberg LR (1990) An alternative "description of personality": the big-five factor structure. J Pers Soc Psychol 59(6):1216

Good PI (2005) Permutation, parametric and bootstrap tests of hypotheses. 3rd Edition. Springer Series in Statistic. Springer, Berlin

Gutman LM, Schoon I (2013) The impact of non-cognitive skills on outcomes for young people. Educ Endow Foundation 59(22.2):2019

Heckman JJ, Kautz T (2012) Hard evidence on soft skills. Labour Econ 19(4):451-464 
Heckman JJ, Kautz T (2014) Fostering and measuring skills; achievement tests and the role of character in American life. In: Heckman JJ, Humphries JE, Kautz T (eds) The myth of achievement tests: the GED and the role of character in American life. University of Chicago Press, Chicago

Heckman JJ, Smith JA (1995) Assessing the case for social experiments. J Econ Perspect 9(2):85-110

Heß S (2017) Randomization inference with Stata: a guide and software. Stata J 17(3):630-651

Hippe R, Jakubowski M (2018) Immigrant background and expected early school leaving in Europe: evidence from PISA; EUR 28866 EN; Luxembourg: Publications Office of the European Union. https://doi.org/10.2760/111445

Huber M (2012) Identification of average treatment effects in social experiments under alternative forms of attrition. J Educ Behav Stat 37(3):443-474

Jackson CK (2017) What do test scores miss? The importance of teacher effects on non-test score outcomes. J Polit Econ 126(5):2072-2107

Kautz T, Heckman JJ, Diris R, TerWeel B, Borghans L (2014) Fostering and measuring skills: improving cognitive and noncognitive skills to promote lifetime success (No. w20749). National Bureau of Economic Research, Cambridge

Knudsen El, Heckman JJ, Cameron JL, Shonkoff JP (2006) Economic, neurobiological, and behavioral perspectives on building America's future workforce. Proc Natl Acad Sci 103(27):10155-10162

Khoury-Kassabri M, Ben-Arieh A (2008) School climate and children's views of their rights: a multi-cultural perspective among Jewish and Arab adolescents. Children Youth Ser Rev 31:97-103

Kolenikov S, Angeles G (2009) Socioeconomic status measurement with discrete proxy variables: is principal component analysis a reliable answer? Rev Income Wealth 55(1):128-165

Lamonica V, Ragazzi E, Santanera E, Sella L (2016a) The role of personal networks in the labour insertion of weak jobseekers. Int J Comput Econ Econom 6(3):315-335. https://doi.org/10.1504/IJCEE.2016.077267

Lamonica V, Ragazzi E, Sella L (2016b) Antenne sociali per la formazione iniziale: un approccio strutturale per la rilevazione dei bisogni. Rassegna Italiana di Valutazione XX(66):59-75. https://doi.org/10.3280/RIV2016-066005

Lleras C (2008) Do skills and behaviors in high school matter? The contribution of noncognitive factors in explaining differences in educational attainment and earnings. Soc Sci Res 37(3):888-902

Lodigiani R, Santagati M (2017) NEET e Garanzia Giovani. Una politica di empowerment per i più svantaggiati? In: Alfieri S, Sironi E (eds) Una generazione in panchina. Da Neet a risorsa per il paese. Vita e Pensiero, Milano, pp 267-276

Losito B, D'Apice A (2003) Democracy, citizenship, participation. The results of the second IEA civic education study in Italy. Int J Educ Res 39(6):609-620

Maćkiewicz M, Cieciuch J (2016) Pictorial personality traits questionnaire for children (PPTQ-C)—a new measure of children's personality traits. Front Psychol 7:498

Mann HB, Whitney DR (1947) On a test whether one of two random variables is stochastically larger than the other. Ann Math Stat 18:50-60

Manski CF (1999) Identification problems in the social sciences. Harvard University Press, Cambridge

MIUR (2019). La dispersione scolastica nell'a.s. 2016/2017 e nel passaggio all'a.s. 2017/2018. https://www.miur. gov.it/documents/20182/2155736/La+dispersione+scolastica+nell\%27a.s.2016-17+e+nel+passa ggio+all\%27a.s.2017-18.pdf/1e374ddd-29ac-11e2-dede-4710d6613062?version=1.0\&t=1563371652741

Nusche D (2009) What works in migrant education?: a review of evidence and policy options. OECD Education Working Papers, No. 22. OECD Publishing, Paris

Ohinata A, van Ours JC (2012) Young immigrant children and their educational attainment. Econ Lett 116(3):288-290

Orr LL, Bloom H, Bell S, Lin W, Cave G, Doolittle F (1994) The national JTPA study: impacts, benefits, and costs of Title II-A. Abt Associates, Bethesda

Osadan R, Reid E (2016) Recent migrants and education in the European Union. Comp J Comp Int Educ 46(4):666-669

Pratt TC, Cullen FT (2000) The empirical status of Gottfredson and Hirschi's general theory of crime: a meta-analysis. Criminology 38(3):931-964

Ragazzi E (2014) Effectiveness evaluation of training programmes for disadvantaged targets. Proced Soc Behav Sci 141:1239-1243. https://doi.org/10.1016/j.sbspro.2014.05.213

Ragazzi E, Sella L (2016) Migration and work: the cohesive role of vocational training policies. Mondi Migranti 1:139-160. https://doi.org/10.3280/MM2016-001008

Rodriguez-Planas N (2012) Longer-term impacts of mentoring, educational services, and learning incentives: evidence from a randomized trial in the United States. Am Econ J Appl Econ 4(4):121-139

Rothbart MK, Ahadi SA, Hershey KL (1994) Temperament and social behavior in childhood. Merrill-Palmer Q 40:21-39

Schanzenbach DW (2014) Does class size matter? National Education Policy Center. Available on http://nepc.colorado. edu/publication/doesclass-size-matter

Sella L (2014) Enhancing vocational training effectiveness through active labour market policies. Procedia Soc Behav Sci 141:1140-1144. https://doi.org/10.1016/j.sbspro.2014.05.192

Shadish W, Cook TD, Campbell DT (2002) Experimental and quasi-experimental designs for generalized causal inference. Houghton Mifflin, Boston

Shiner RL (1998) How shall we speak of children's personalities in middle childhood? A preliminary taxonomy. Psychol Bull 124(3):308

Thibert R (2013) Le décrochage scolaire: diversité des approches, diversité des dispositive. Dossier d'actualité. Lyon, ENS de Lyon, Veille \& Analyses IFÉ, vol 84(5).

Tierney JP, Baldwin-Grossmann J, Resch NL (1995) Making a difference. An impact study of big brothers big sisters. Report, Public/Private Venture, https://www.ncjrs.gov/App/Publications/abstract.aspx?|D=162036

Verhelst N, Van Avermaet P, Takala S, Figueras N, North B (2009) Common European Framework of reference for languages: learning, teaching, assessment. Cambridge University Press, Cambridge

Zecca V, Mazzei S (2018) II progetto ENABLE Self-Learning for Arab speaking refugee children Building a concept for mother tonque trainers and teachers. Culture e Studi del Sociale 3(1):111-115

\section{Publisher's Note}

Springer Nature remains neutral with regard to jurisdictional claims in published maps and institutional affiliations. 